\title{
The Analysis of Sociopath of Louis Bloom's Character in Nightcrawler
}

\author{
Yuli Angraini \\ English Education Department \\ University of Riau Kepulauan \\ angraini_yuli@yahoo.com
}

\begin{abstract}
The writer chose one of literary works-film entitled "The Analysis of Sociopath of Louis Bloom's Character in Nightcrawler" to be anlyzed. The writer interested to analyze the main character in this film-Louis who used all people around him for the sake of his own intention. He even did not care if people whom he used finally dead. He even recorded the murded scene as calm as it was nothing just casual events that could happen anytime. The purpose of this study was to analyze the types of sociopath character in Louis Bloom and to describe how it can affect his perspective towards his goal. The method of this study was a descriptive. The writer watched Nightcrawler movie to observe the main chharacter and he manipulated people to smooth his way. The writer also read the movie script to understand Louis' character deeper. To analyze the sociopath of main character, the writer used the psychological approach of Grossman's theory of psychoanalysis
\end{abstract}

Keywords: sociopath character and psychological approach

\section{INTRODUCTION}

Life is a drama. When people said about that, they are right. In life itself, human system almost similar with other creature. The strongest will be survived while the weakest, shattered into pieces. It is all about the power of oneself to let the life control him or her or be the one who conquer that and turn all the craziness in life into a peaceful thing and become a winner. Film, novel, poem often presented life description. Though they are different medium but they are the same if related to the participants - Speaker and audience or writer and reader. In film, the writer of the script communicated with his or her audience by the language he or she conveyed and acted by the actor and actresses. If they were failed to perform as what the writer wanted to see then the rest of the film will be boring as the audiences cannot grasp what the writer tried to connect with them as audiences.

Many thousands of movies are adaptations from historical or literary sources. Hence the recent internet vernacular of "litflicks"- -literature adapted into flicks, the flickering 
medium of the motion pictures. A movie gets to places literature and history do not. And then it delivers that place to its audience in a way literature and history cannot. The audience, in turn, must use their eyes for a movie to work. After all, are not literature and history forms of communication which are more available to a blind person? With literature and history the audience sees with their inner eye, not as much with their outer, physical eye. "Film creates a fully defined and immediate physical reality that requires dramatization and exploration; it brings characters visually realized into direct relationship with their environment and in immediate proximity to the viewer (Konigsberg, 1997: 6) in Dean (2015).

There are many characters in this world especially in life. Some people say that it needs a whole life time to really know about someone's character especially to themselves. Even blood tie like parents or family hardly can explain this phenomenon. For example: When someone really fell in love with her or his love of life, all things seemed so perfect. No flawless at all. As when in the beginning of relationship, people tend to hide who they really are in order to impress their partner. If they do not do that, it will break their own expectation to one another. Other factors like age factor for women who must find their life partner as soon as possible otherwise they cannot pregnant anymore in some case burden them somehow. While in another case like a man who already reached certain age such as 28 age years old which categorized as already mature and capable of having long life relationship like marriage must face some forces from his internal blood path, that is, his parents' expectation who want to get their own grandchildren from their son. This might cause his parents to push that man to do what they want though must break all rules like culture and the most unbreakable factor like a religion. The fact that they are the parents of the man can manipulate that man's mind which lead him to one conclusion of mind that his parents suffered. Although that condition looks so superficial for common people but this can cause mental illness. The man feels the need to protect his parents from suffering apart from his as the result of some tensions that he cannot able to cope with that anymore. That man may start to torture his love's mind by pushing what he and his parents want regardless some undeniable factors like culture especially religion and things like family boundaries. The threat, parents' principles from both of sides and life too are environment factors that can shape one's mind to be a sociopath. However, the term of sociopath is not usual for some people. People usually get used to with the term psychopaths that they hear from movie, television and newspaper as in their imagination the psychopath is more famous and sometimes they make it interchangeable. Both psychopaths and sociopaths share some of the typical traits, such as lack of empathy, impulsive behavior, and inability to 
abide by social norms, but a sociopath is considered a mental disorder according the Diagnostic and Statistical Manual of Mental Disorders (DSM-IV). This disorder is listed as a personality disorder of the Cluster B (Anti-social) list, which also includes separate categories of borderline, histrionic, and narcissistic disorders. The requirements for psychopathy differ slightly due to the Psychopathy Checklist created by Robert D. Hare and is implemented instead of the guidelines of the Anti-Social Personality Disorder. However, psychopathy is considered a form of the Anti-Social Personality Disorder.

Psychopaths are often found to be suspicious and interpret all aggressive behavior to be against them, and extremely undeserved. They are generally organized individuals, and often with successful careers and normal relationships. Many of people know, or have at least come in contact with a psychopath during our lifetime. When it comes to criminal psychopaths, they often plan their crimes well in advance, and sometimes, even years ahead of time while sociopaths are generally incapable of maintaining relationships and jobs. They are usually disorganized and have a short fuse to commit violence or abuse against others. The inability to plan for the future makes them excessively impulsive. Crime seems a natural way of life for them. Other characteristics include the lack of safety for themselves or anyone around them, promiscuity, and heightened levels of deceitfulness. By referring to those explanantion, the writer brought that into surface to be analyzed into a descriptive study entitled, " THE

\section{ANALYSIS OF SOCIOPATH OF LOUIS BLOOM'S CHARACTER IN NIGHTCRAWLER."}

According to the current bible of psychiatric labels, the Diagnostic and Statistical Manual of Mental Disorders IV of the American Psychiatric Association in Stout (2005: 17) said that the clinical diagnosis of "antisocial personality disorder" should be considered when an individual possesses at least three of the following seven characteristics: (1) failure to conform to social norms; (2) deceitfulness, manipulativeness; (3) impulsivity, failure to plan ahead; (4) irritability, aggressiveness; (5) reckless disregard for the safety of self or others; (6) consistent irresponsibility; (7) lack of remorse after having hurt, mistreated, or stolen from another person. The presence in an individual of any three of these "symptoms," taken together, is enough to make many psychiatrists suspect the disorder.

\section{Sociopathic Tendencies in Adults}

There are certain typical sociopath traits that makes identifying such individuals easy. Initially one may be charmed by their wit and verbal tact. However, soon one realizes that 
beneath the façade lies a cold, self centered individual. Here are some traits that can be used as a sociopathic tendencies checklist to determine if an individual suffers from this disorder or not:

1. Disregard for rights of others

2. Considerable superficial charm

3. Above average intelligence

4. Incredible glibness

5. Inflated sense of self that convinces a sociopath that whatever he does is his right

6. Conning and manipulative

7. Lack of empathy. Rather views pain of his victims with contempt and takes advantage of their distress

8. Failure to relate emotionally and promiscuous behaviour. Even if they do appear committed, it would be superficial. They would use such relation for ulterior motives

9. Lack of remorse or shame. They view everyone around them as objects and opportunity to achieve their goals. Hence sociopaths keep violating other's rights without any guilt

10. Streak of violence.

11. Pathologically ego centric and self centered.

12. Impulsive behaviour. Their belief that they are always right and inability to submit to authority makes them impulsive. These people hardly stay on a job for long.

13. Addiction to drugs and alcohol. 
14. Unreliable and irresponsible.

In line with it, Grossman (2015) made a clear understanding about the classification of sociopath and other personalities disorder.

1. Covetus Sociopath

Feels deliberately deprived \& denied, rapacious, very greedy, jelous, envoues, begrudging, endlessly yearning, seeks retribution. Finds pleasure in actual taking more than having.

2. Nomadic / Schizoid-Avoidant

Feels fated to be in the condition he or she is, condemned, Ill-destined, cast aside; the type includes those roaming like a gypsy, dropouts, misfits, long term homeless, impulsively harmful.

\section{Risk-Taking / Histrionic Sociopath}

Rushes to danger, likes to venture, vibrant, bold, daring, intrepid, fearless, reckless, impulsive, excited by threat to life.

4. Reputation Defending / Narcissistic Sociopath

Defends his reputation of unflawed, the one with courage, unbreakable, dominant, undefeatable, formidable, untouchable; furious/relentless when status in question, overreacts to little things.

5. Levolent / Sadistic-paranoid Sociopath

Belligerent, aggressive, sarcastic, rancorous, biting, vicious, brutal, malignant, fearless, shameless, fierce, resentful; anticipates to be betrayed and seeks for punishment, yearns for revenge, has cruel disregard for others.

There are six characteristics (sub-types) of sociopaths referred to from various studies and interpretations:

\section{Narcissistic}


This type of sociopath is considered a form of the Narcissistic Personality Disorder. These individuals usually do not want to be helped and do not care if anyone disagrees with them. They are manipulative and exhibit absolutely no remorse for their actions. There is nothing that will stop them from achieving their goal.

\section{Entitled}

This type of sociopath feels that self needs justify the means. They feel no shame in their actions, and often enjoy making fun of authority.

\section{Amoral}

Lack of morality and no sense of guilt drive this type of sociopath to commit amoral acts. They have a primitive sense of self and have no compassion to other people's pain. They enjoy torturing animals or watching animals kill each other. By causing pain to others, they receive satisfaction in attaining what they want most.

\section{Alienated}

This type of sociopath lacks the standard empathy and effectional attachment from lack of love and affection during the developmental early years, which leads to disaffiliated, disempathic, hostile, and cheated personality types.

\section{Aggressive}

This type of sociopath has a deep fulfillment of hurting or frightening others. This gives them power and a strong sense of importance, dominance, and control. Sadism can be one of the dysfunctions of this type.

\section{Dyssocial}

This type of sociopath has been described as normal temperamentally and psychologically, but they have a strong connection to subculture norms, sometimes in a predatory nature. 


\section{METHODOLOGY}

The writer used a psychological approach through the theory of Grossman (2015) "Advancing Personality Theories and Assesssment. In collecting the data, the writer conducted the library research in which the data was divided into two kinds - primary and secondary data. Primary data is obtained by reading and grasping the behavior of main character by watching the movie entitled "Nightcrawler". In analyzing the main character, the writer used psychoanalysis approach which was proposed by Grossman (2015).

\section{RESULTS}

After the writer watched the film, she found there were three dominant of sociopath character in Louis Bloom. They were:

\section{Risk-Taking / Histrionic Sociopath}

Rushes to danger, likes to venture, vibrant, bold, daring, intrepid, fearless, reckless, impulsive, excited by threat to life.

\section{Data 1}

\section{LOU}

You're not listening, Nina. I happen to know you haven't stayed at one station for more than two years at a time, and you're coming up on two years soon. So I can imagine you have a contract for that length of time and that ratings during the next week will directly affect that.

\section{NINA}

You're threatening if I don't ...

LOU

I'm negotiating.

\section{NINA}

You're threatening to stop selling to me.

\section{LOU}

That's your choice. The true price of any item is what someone's willing to pay. You want something and I want you. 


\section{Analysis and Description:}

In that dialogue, it could be seen that Lou knew who he dealt with. He understood very well his victim. Though his victim knew she was used but Lou manipulated her mind by said the word "negotiating" to get what he wanted. He also knew he would eventually achieve his goal by doing so. He did not have to yell or force his victim but he led her to the choice that no doubt obeyed by her.

\section{Data 2}

\section{LOU}

I can't make people do things, Rick. You have a choice to do this and I have a choice if you don't.

\section{RICK}

You threatening to fire me? Hey, I got something too. Not calling criminals in, waiting for 'em to start so you can film it, that's against the law.

The cops would be majorly interested no doubt. I want more money.

\section{LOU}

We can reopen negotiations, Rick, but remember that when it comes to your work reputation you can't un-ring the bell.

\section{RICK}

I want half of whatever we make tonight .

\section{Analysis and Description:}

In that dialogue between Lou and his partner, Lou kept maintaining to make his victim knew his position. He made it by put his victim into a "comfort" zone but left his partner also into" a danger" position after "blackmailed" him.

\section{Data 3}

\section{RICK}

I'm not going out there. I'm not doing

it.

LOU

You're making a mistake. 


\section{RICK}

I don't care about my title.

\section{LOU}

What if my problem wasn't that I don't understand people but that I don't like them? What if I was the kind of person who was obliged to hurt you for this? I mean physically. I think you'd have to believe afterward, if you could, that agreeing to participate and then backing out at the critical moment was a mistake. Because that's what I'm telling you, as clearly as I can.

\section{Analysis and Description:}

In that dialogue, Lou already gave a bold statement by said tah he was kind of person who could hurt him physically and he meant it at the time he said it to his partnet that threaten his victim somehow because his partner denied to do what Lou wanted.

Reputation Defending / Narcissistic Sociopath

Defends his reputation of unflawed, the one with courage, unbreakable, dominant, undefeatable, formidable, untouchable; furious or relentless when status in question, overreacts to little things.

\section{Data 4}

\section{LOU}

Coldwater has places to pass. I can't get around this person in front of us until Ventura.

\section{RICK}

It's the same argument. I said this route and you should have said something if you wanted to take Coldwater.

\section{LOU}

I thought you'd worked in other factors. If I didn't think you could do better I wouldn't ride you about routes. You have to know that, Rick. I think it's just possible that I have a higher opinion of you than you have of yourself. 


\section{Analysis and Description:}

In that dialogue, Lou defended his reputation as his partner did not follow his direction and emphasize his dominant position by said that he had a higher opinion of his partner had than his partner had of himself. In this case, Lou showed his power to his partner.

\section{Data 5}

\section{RICK}

What's in there?! What's going on?!

\section{LOU}

You should have walked in and looked, Rick. If you were half-curious. That's what I'm paying you to do. You need to show initiative. There's no better way to achieve job security than by making yourself an indispensable employee.

\section{RICK}

I heard gunshots. There was blood on the floor.

55.

\section{LOU}

All the more reason. You might have helped me. You might have learned a new skill that made you more useful and put us on a track toward growth .

\section{Analysis and Description:}

In that dialogue, Lou felt furious as his partner had no initiative to be creative. This made his goal stucked. He did not like excuses. He never accepted the failure that could break all his goal.

Levolent / Sadistic-paranoid Sociopath

Belligerent, aggressive, sarcastic, rancorous, biting, vicious, brutal, malignant, fearless, shameless, fierce, resentful; anticipates to be betrayed and seeks for punishment, yearns for revenge, has cruel disregard for others.

\section{Data 6}




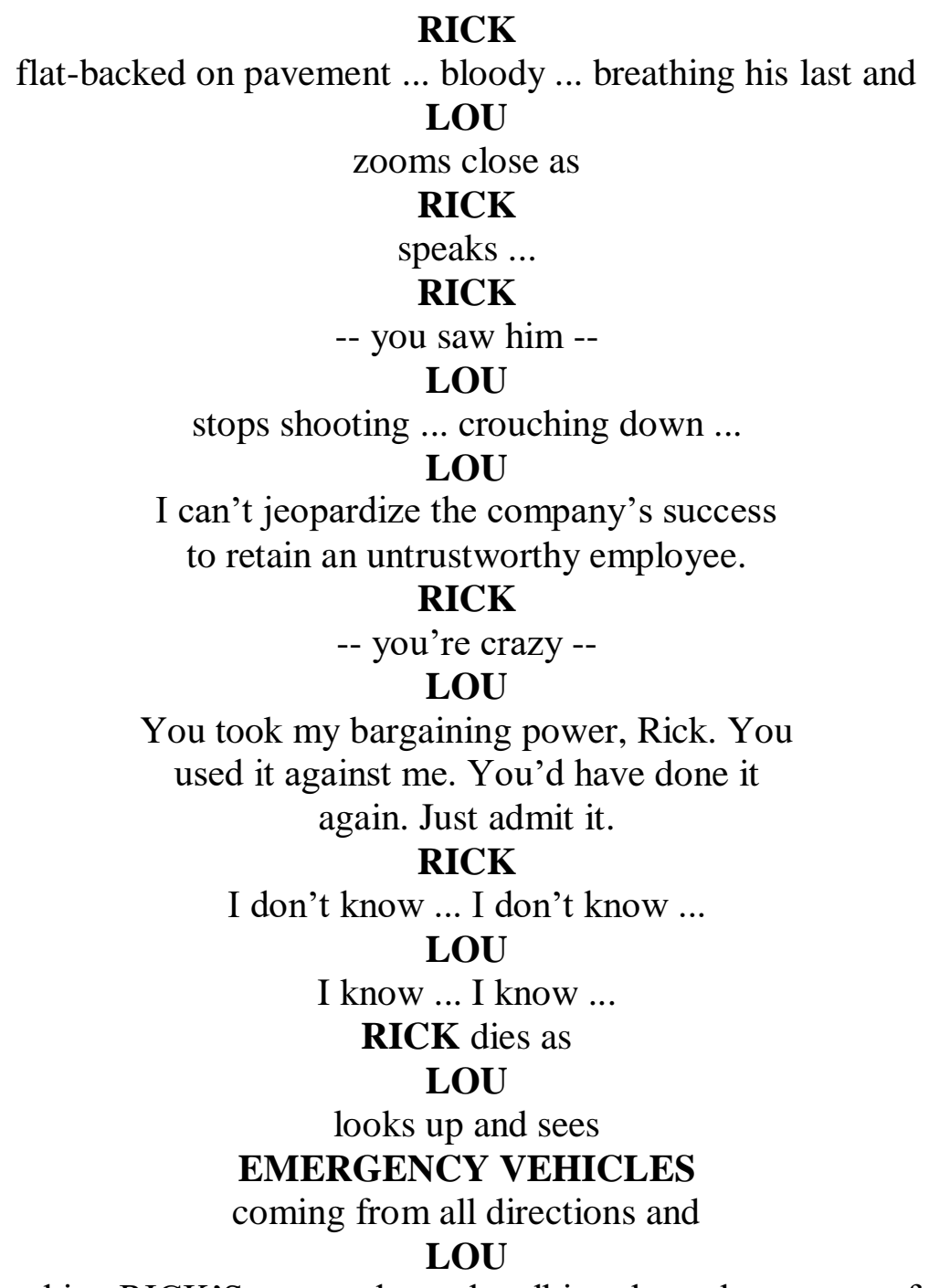

\section{Analysis and Description:}

There was a frame scene where Lou let his partner being shot by the criminal. He trapped his partner as his revenge to his greediness to money. That was emphasized by his word that his partner took his bargaining power to his partner who dying while just looked at him with his cold eye and recorded him as the source of his news to get more money. Lou just left his partner like that without helped him. He just used his partner to get new rating in his own production.

\section{DISCUSSION}

A sociopath is commonly called as a person with a psychopathic personality whose behavior is antisocial, often criminal, and who lacks a sense of moral responsibility or social 
conscience. The main character in this film-Louis Bloom is a stringer and also a photojournalist with a police scanner darkly patrolling the hyperreal streets of nocturnal Los Angeles searching for his next turn. From the film, it could be seen, there were three types of sociopath in his character. They were (1) Risk-taking / Histrionic Sociopath; (2) Reputation Defending/ Narcissistic Sociopath and (3) Levolent / Sadistic-paranoid Sociopath. Among them, the dominat of sociopath character in him was Ris-taking / Histrionic Sociopath. This character led him to achieve his goal fearles and often close to danger, however it made him unbeatable. He even had no mercy to his partner when he knew his partner hindered him from success and not follow his rule that he already emphasized. He applied all possible and even impossible ways just to smooth his intention though must manipulate people around him and put them in danger and death.

\section{REFERENCES}

Dean, John. (2015). Adapting history and literature into movies. American Studies Journal. Number 53 (2009)DOI 10.18422/53-07Cinematographic Adaptation, Lincoln. Retrieved from: http://www.asjournal.org/53-2009/adapting-history-and-literature-into-movies/.

Grossman, T. Millon. (2015). Sociopathic personality disorder. The Millon Personality Group. Retrieved from: http://depressiond.org/sociopath-sociopathic-personality-disorder/

Konigsberg, Ira. (1997). The complete film dictionary, 2nd ed. London, New York: Bloomsbury.

Shope,Carlleen.(__ Sociopathic tendencies. Retrieved from: http://carlleenshope.weebly.com/uploads/4/0/3/6/4036917/sociopathic_tendencies_2.pdf.

Stout, Martha. (2005). The sociopath next door. Broadways Book: New York. Retrieved from: https://marucha.files.wordpress.com/2014/06/the-sociopath-next-door.pdf. 